\title{
Preparation and Electrochemical Performance of Hollow Activated Carbon Fiber Self-Supported Electrode for Supercapacitor
}

\author{
Zhenmin Jiao ${ }^{1,3}$, Qianqian $\mathrm{Wu}^{1}$, Ludwig Cardon ${ }^{3, *}$, and Jun Qiu ${ }^{1,2, *}$ \\ ${ }^{1}$ School of Materials Science and Engineering, Tongji University, Shanghai 201804, PR China \\ ${ }^{2}$ Key Laboratory of Advanced Civil Engineering Materials (Tongji University), Education of Ministry, Shanghai 201804, PR China \\ ${ }^{3}$ Centre for Polymer and Material Technologies, Department of Materials, Textiles and Chemical Engineering, Ghent University, \\ Technologiepark 130, Zwijnaarde, Ghent 9052, Belgium
}

\begin{abstract}
Hollow activated carbon fiber (HACF) with high specific surface area and high charge storage capability was prepared by pre-oxidation, carbonization and $\mathrm{KOH}$-activation from polyacrylonitrile (PAN). HACF was used as self-supported working electrode directly without any binder and conductive agent. The effect of the activation time on specific surface area of HACF was studied intensively. The results show that the specific surface area of HACF increased with the increase of activation time from $0.5 \mathrm{~h}$ to $1.5 \mathrm{~h}$, and then decreased with further increase of activation time. Highest specific surface area of $1873 \mathrm{~m}^{2} \mathrm{~g}^{-1}$ and micropore volume of $0.61 \mathrm{~cm}^{3} \mathrm{~g}^{-1}$ were obtained in HACF activated for $1.5 \mathrm{~h}$. Electrochemical properties of HACF can be improved with increase of activation time, but excessive activation results in the decrease of specific surface area and increase of internal resistance of HACF. The self-supported electrode of HACF possesses a large specific capacitance of $323 \mathrm{~F} \mathrm{~g}^{-1}$ at $0.05 \mathrm{~A} \mathrm{~g}^{-1}$ and $216 \mathrm{~F} \mathrm{~g}^{-1}$ at $1 \mathrm{~A} \mathrm{~g}^{-1}$. Therefore, HACF can be a promising self-supported electrode for high performance supercapacitors.
\end{abstract}

Keywords: Hollow Activated Carbon Fiber, Self-Supported Electrode, Supercapacitor, Activation Time.

\section{INTRODUCTION}

Supercapacitors, a promising power source, have attracted intensive attention since they can provide energy density by orders of magnitude higher than dielectric capacitors, providing greater power density and longer cycling ability than batteries [1-6]. Electrode materials have a great effect on the electrochemical properties of supercapacitors. Carbon materials for energy storage systems have drawn extreme attention due to their accessibility [7-9], especially for electrode materials, different allotropes (graphite, diamond, fullerenes/nanotubes), various micro textures, a rich variety of dimensionalities from 0 to $3 \mathrm{D}$, availability in various forms (powder, fiber, foam, fabric and composite) and relatively low cost. Many carbon materials such as electrodes, carbon nanotubes [10-12], activated carbon [13-15], graphene [16-18] and activated carbon fiber [19-21] have been studied. Among them,

*Authors to whom correspondence should be addressed. active carbon fiber has been widely studied because of large specific surface area, light weight and ease of production. Moreover, plenty of micropores open directly to the exterior of active carbon fiber with fast adsorption/desorption of molecules [22, 23]. Ma et al. [24] prepared microporous carbon nanofiber through electrospinning and activation processing from resole-type phenolic resin. The maximum specific capacitance of $256 \mathrm{~F} \mathrm{~g}^{-1}$ and high specific surface capacitance of $0.51 \mathrm{~F} \mathrm{~m}^{-2}$ were achieved at $0.2 \mathrm{~A} \mathrm{~g}^{-1}$. Xu et al. [21] prepared activated carbon fiber $(\mathrm{ACF})$ by pyrolyzing polyacrylonitrile fiber and activation. The surface area of the ACF was as high as $3291 \mathrm{~m}^{2} \mathrm{~g}^{-1}$. Moreover, the pore volume of the carbon reached $2.162 \mathrm{~cm}^{3} \mathrm{~g}^{-1}$, and the specific capacitance reached $196 \mathrm{~F} \mathrm{~g} \mathrm{~g}^{-1}$. So far, activated carbon fiber has been widely applied in electronic industry [25]. With further research, scientists have discovered a kind of activated carbon fiber with hollow structure (HACF). The special hollow structure, rich porous structure in inner and outer 
surface of HACF, provides larger surface area and higher adsorption-desorption rate compared to solid active carbon fiber [26]. Meanwhile, the special hollow structure of HACF can result in fast ion/electron transfer and sufficient contact between active materials and electrolyte in a supercapacitor [27]. HACF used as supercapacitors electrodes was reported in 2013 by $\mathrm{Du}$ [28] that ramie fiber were used as precursors to produce $\mathrm{HACF}$ with a specific capacitance as high as $287 \mathrm{~F} \mathrm{~g}^{-1}$ and surface area of $2087 \mathrm{~m}^{2} \mathrm{~g}^{-1}$. The electrode was prepared by mixing HACF, acetylene black and PTFE, kneading and then rolling to nickel grid that served as a current collector.

However, many studies have proven that addition of binder (PTFE) in electrode increased the resistance, reducing the discharge of the capacitor [29]. Self-supported electrodes which did not use binder, conductive agent or even current collector have been widely studied due to its low cost, stable structure and excellent electrochemical performance [30]. There were mainly two methods to prepare self-supported electrodes: (1) combining active electrode material on the surface of self-supported substrate (carbon cloth, nickel grid, sponge) [31]; (2) directly using self-supported materials with electrochemical properties as electrode materials via electro-deposition, CVD, electrospinning and hydrothermal method [32-36]. Huang et al. [36] directly used PANI/PVA hydrogel as selfsupported electrode for supercapacitor. The electrochemical properties of PANI/PVA hydrogel electrodes showed high specific capacitance of $240 \mathrm{~F} \mathrm{~g}^{-1}$ at current density of $1 \mathrm{~A} \mathrm{~g}^{-1}$. Zhao et al. [37] prepared coal based active carbon nanofiber to apply as binder-free electrode which showed a specific capacitance of $230 \mathrm{~F} \mathrm{~g}^{-1}$ at a current density of $1 \mathrm{~A} \mathrm{~g} \mathrm{~g}^{-1}$. To our knowledge, there is no report respected to HACF as a self-supported electrode.

In present study, HACF was used as self-supported electrode without binder, conductive agent and current collector. HACF with high surface area, well developed porosity and good electrochemical performance were prepared from hollow polyacrylonitrile (PAN) fiber through the process of stabilization, carbonization and $\mathrm{KOH}-$ activation. The effects of the activation time on specific surface area and electrochemical properties were discussed in detail. The self-supported electrode of HACF possessed excellent electrochemical performance.

\section{EXPERIMENTAL DETAILS}

\subsection{Preparation of Hollow Activated} Carbon Fiber (HACF)

Polyacrylonitrile (PAN) hollow fiber with outside diameter $1.0 \mathrm{~mm}$, inner diameter $0.6 \mathrm{~mm}$ obtained from ShuiFuYuan environmental protection Co., Ltd., Shenzhen were the precursors of HACF. The preparation process of HACF was as follows: (1) PAN hollow fiber was immersed in ethanol for $8 \mathrm{~h}$ and dried at room temperature; (2) the dried PAN hollow fiber undergoes a stabilization step at
$230{ }^{\circ} \mathrm{C}$ for two hours in air atmosphere; (3) the fiber was carbonized at $700{ }^{\circ} \mathrm{C}$ for one hour at nitrogen atmosphere to obtained PAN based hollow carbon fiber; (4) the hollow carbon fiber was impregnated with $40 \mathrm{wt} \% \mathrm{KOH}$ solution for 12 hours and dehydrated in an oven at $80{ }^{\circ} \mathrm{C}$ during 10 hours. The $40 \mathrm{wt} \% \mathrm{KOH}$ impregnated hollow carbon fiber was placed in a ceramic boat and activated in a horizontal tubular furnace under nitrogen flow. The temperature was increased from ambient temperature to final temperature $\left(850{ }^{\circ} \mathrm{C}\right)$ at a heating rate of $3{ }^{\circ} \mathrm{C} \mathrm{min}{ }^{-1}$ with retention time of 1 hour. The activated samples were washed by distilled water to neutral and then dried to obtain HACF with outside diameter of $0.8 \mathrm{~mm}$ and inner diameter of $0.5 \mathrm{~mm}$. HACF prepared in this experimental setup remained its original shape of PAN hollow fibers.

\subsection{Characterization}

Scanning electron microscope (SEM) Quanta FEG 200 field emission scanning electron microscopy was applied to observe the morphology of HACF samples. The $\mathrm{N}_{2}$ adsorption-desorption isotherms of HACF were measured at $77 \mathrm{~K}$ using ASAP2020 (Micromeritic, USA) in order to determine the specific surface areas and pore structure parameters. Prior to measurement, samples were outgassed at $300{ }^{\circ} \mathrm{C}$ for 24 hours in a vacuum oven. The BET equation was used to calculate the specific surface area. The pore size distribution of HACF was calculated based on the density functional theory (DFT).

\subsection{Electrochemical Measurements}

All electrochemical behaviors of the HACF electrodes were performed by cyclic voltammetry (CV), galvanostatic charge-discharge, and electrochemical impedance spectroscopy on a CHI660E electrochemical workstation (Shanghai, Chenhua Limited Co.) in a conventional threeelectrode system in which $\mathrm{Pt}$ and $\mathrm{Ag} / \mathrm{AgCl}$ electrode were used as counter and reference electrode. The prepared $\mathrm{HACF}$ was directly used as a working electrode without conductive agent and binder. $1 \mathrm{~mol} \mathrm{~L}^{-1} \mathrm{H}_{2} \mathrm{SO}_{4}$ solution was used as electrolyte. The current change curves of the HACF in the scanning rate of $0.5 \mathrm{~V} \mathrm{~s}^{-1}, 0.3 \mathrm{~V} \mathrm{~s}^{-1}$, $0.2 \mathrm{~V} \mathrm{~s}^{-1}, 0.1 \mathrm{~V} \mathrm{~s}^{-1}, 0.05 \mathrm{~V} \mathrm{~s}^{-1}, 0.03 \mathrm{~V} \mathrm{~s}^{-1}$ and $0.01 \mathrm{~V} \mathrm{~s}^{-1}$ were measured by cyclic voltammetry test. The voltage range for the cyclic voltammetry test varied from 0 to $1 \mathrm{~V}$. Galvanostatic measurement varied from 0 to $0.8 \mathrm{~V}$. The specific capacitance is calculated with Eq. (1) using the integral current areas of the discharge curves.

$$
C=\frac{I \Delta t}{m \Delta V}
$$

Where $C\left(\mathrm{~F} \mathrm{~g} \mathrm{~g}^{-1}\right)$ is the specific capacitance, $I(\mathrm{~A})$ is the discharge current, $\Delta V(\mathrm{~V})$ is the potential window of discharge, $\Delta t(\mathrm{~s})$ is the discharge time and $m(\mathrm{~g})$ is the mass of the active material. 


\section{RESULTS AND DISCUSSION}

\subsection{Structure of HACF}

Hollow activated carbon fiber was prepared by preoxidation, carbonization and activation of PAN fiber. SEM images of hollow activated carbon fiber were shown in Figure 1. It can be seen from Figures 1(a)-(c) that HACF has two surfaces and a finger-like porous layer on the cross section. The hollow structure and porous layer can be used to store electrolytes and produce electrostatic attraction. After $\mathrm{KOH}$ activation, a large number of micropores and mesopores can be directly exposed to the inner and outer surface of HACF. Due to the limitations of SEM, only few macropores can be observed at the surface of HACF, illustrated in Figure 1(d). Micro- and mesopores at HACF-surface are in direct contact with the electrolyte and thus reduce the ion-diffusion length. Meanwhile, the self-supported structure which acts as an electrode avoids the negative effect brought by binder, conductive agent and current collector. All of these advantages provide beneficial conditions for the hollow activated carbon fiber as a working electrode.

To understand the influence of activation time on the specific surface area of HACF, the HACF was characterized by $\mathrm{N}_{2}$ adsorption-desorption analysis. The nitrogen adsorption isotherms and specific surface area of HACF prepared with different activation time are shown in Figure 2. As shown in Figure 2(a), the $\mathrm{N}_{2}$ isotherms of samples exhibited typical type I isotherms with inconspicuous hysteresis loop which are characteristics of highly microporous materials. Maximum and minimum adsorption volume was obtained at $1.5 \mathrm{~h}$ and $2.5 \mathrm{~h}$ respectively. It can be seen from Figure 2(b) that specific surface area of
HACF increases with the increase of activation time from $0.5 \mathrm{~h}$ to $1.5 \mathrm{~h}$. When the activation time further increases, specific capacitance and surface area of HACF decrease because collapse of pores. HACF for $1.5 \mathrm{~h}$ activation possesses the highest specific surface area of $1873 \mathrm{~m}^{2} \mathrm{~g}^{-1}$, while $\mathrm{HACF}$ for $2.5 \mathrm{~h}$ activation has specific surface area of only $1406 \mathrm{~m}^{2} \mathrm{~g}^{-1}$. In order to quantitatively understand the pore structure of the two typical samples, the characteristic porosity of HACF for $1.5 \mathrm{~h}$ and $2.5 \mathrm{~h}$ activation are given in Table I. HACF for $1.5 \mathrm{~h}$ activation shows larger surface area and pore volume than for $2.5 \mathrm{~h}$ activation. However, fraction of micropore volume in any sample is above $75 \%$ which indicates a small amount of mesopores in HACF. From the sharp decrease of total pore volume in HACF activated for $2.5 \mathrm{~h}$, it can be deduced that pore collapsing from excessive activation will be the possible main reason for the decrease of total pore volume and specific surface area of HACF.

\subsection{Electrochemical Properties of HACF Self-Supported Electrode}

$\mathrm{HACF}$ with outside diameter of $0.8 \mathrm{~mm}$ and inner diameter of $0.5 \mathrm{~mm}$ was selected as working electrode, as illustrated in Figure 3. The electrode was clipped by fixtures and then immersed in electrolyte. The electrochemical performance of HACF electrode was tested via three electrode system.

Electrochemical impedance spectra measurements were performed to investigate the resistance change of HACF electrode. Electrochemical impedance spectra of HACF electrodes with different activation time are presented in Figure 4. Ideal curves of electrochemical impedance spectra present a straight line, which is nearly perpendicular
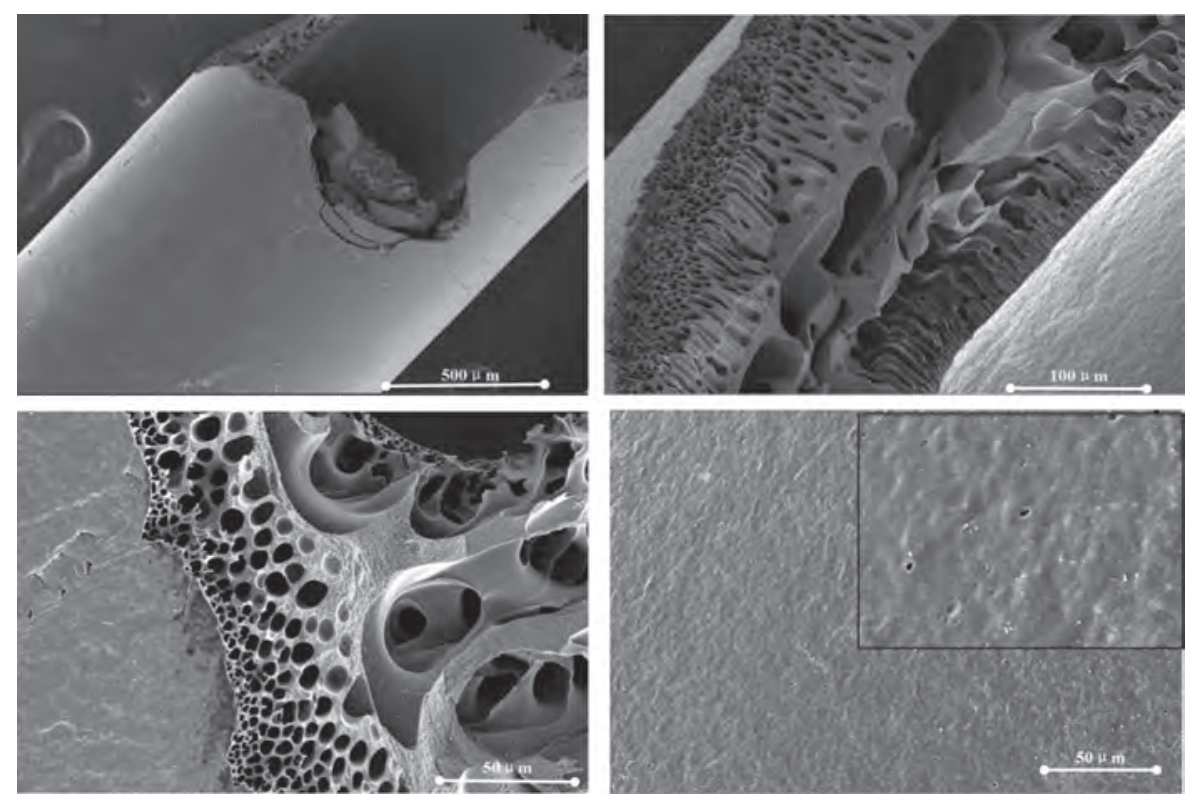

Figure 1. SEM images of hollow activated carbon fiber (a) HACF; (b, c) finger-like porous layer of HACF; (d) surface of HACF, the inset is magnification figure of $\mathrm{d}$. 
(a)

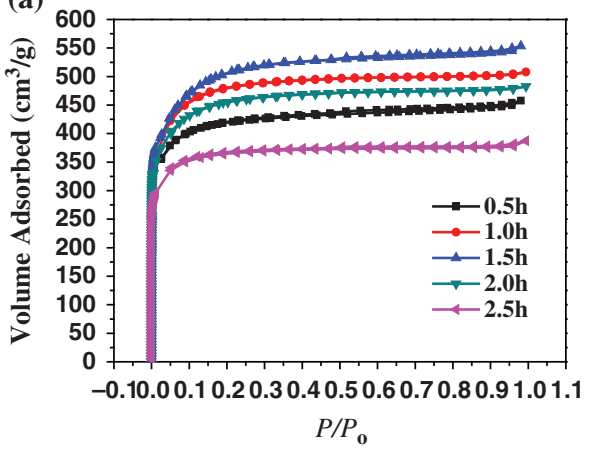

(b)

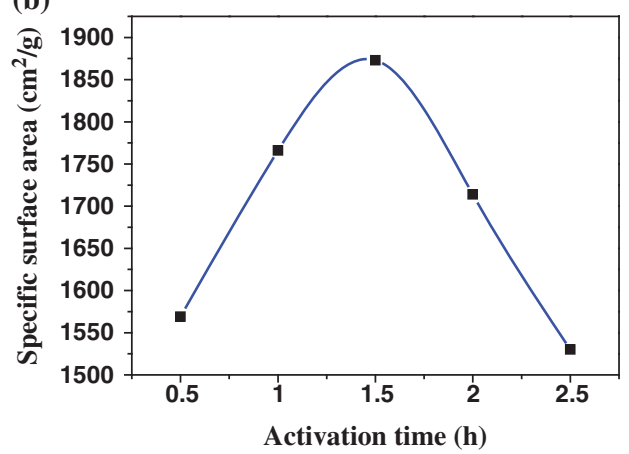

Figure 2. (a) $\mathrm{N}_{2}$ adsorption isotherms of HACF electrodes prepared with different activation time; (b) specific surface area of HACF prepared by different activation time.

Table I. Characteristics of porosity of HACF electrodes prepared with activation time.

\begin{tabular}{lccccc}
\hline Sample & $\begin{array}{c}S_{\mathrm{BET}} \\
\left(\mathrm{m}^{2} \mathrm{~g}^{-1}\right)\end{array}$ & $\begin{array}{c}V_{\text {Total }} \\
\left(\mathrm{cm}^{3} \mathrm{~g}^{-1}\right)\end{array}$ & $\begin{array}{c}V_{\text {Micro }} \\
\left(\mathrm{cm}^{3} \mathrm{~g}^{-1}\right)\end{array}$ & $\begin{array}{c}D_{p} \\
(\mathrm{~nm})\end{array}$ & $\begin{array}{c}F_{\text {Micro }} \\
(\%)\end{array}$ \\
\hline HACF-1.5 h & 1873 & 0.80 & 0.61 & 1.72 & 76 \\
HACF-2.5 h & 1406 & 0.59 & 0.49 & 1.70 & 83 \\
\hline
\end{tabular}

Notes: $S_{\text {BET }}$ : Specific surface areas using BET equation; $V_{\text {Total }}$ : Total pore volume; $V_{\text {Micro }}$ : Micropore volume; $D_{p}:$ Average pore diameter; $F_{\text {Micro }}:$ Fraction of micropore volume.

to the horizontal axis. However, many electrodes cannot present the ideal curves due to their internal resistance. A semicircle is observed in all HACF electrodes, which indicates the charge-transfer resistance from electrolytes moving through the electrodes. HACF for $1.5 \mathrm{~h}$ activation possesses much smaller resistance compared with other electrodes. This may be attributed to the large specific surface area and large micropores/mesopores volume of $\mathrm{HACF}$ for $1.5 \mathrm{~h}$ activation. A short $45^{\circ}$ Warburg region at low frequencies in $\mathrm{HACF}$ electrodes indicates the fast ion transport at the electrode electrolyte interface. The special self-supported structure of HACF electrode avoids the negative effect of binder (PTFE). Even more, micropores and mesopores expose on the surface of HACF electrode directly, which can decrease the electrolyte ions transfer path.

The cyclic voltammograms (CV) of HACF prepared with different activation time are presented in Figure 5.

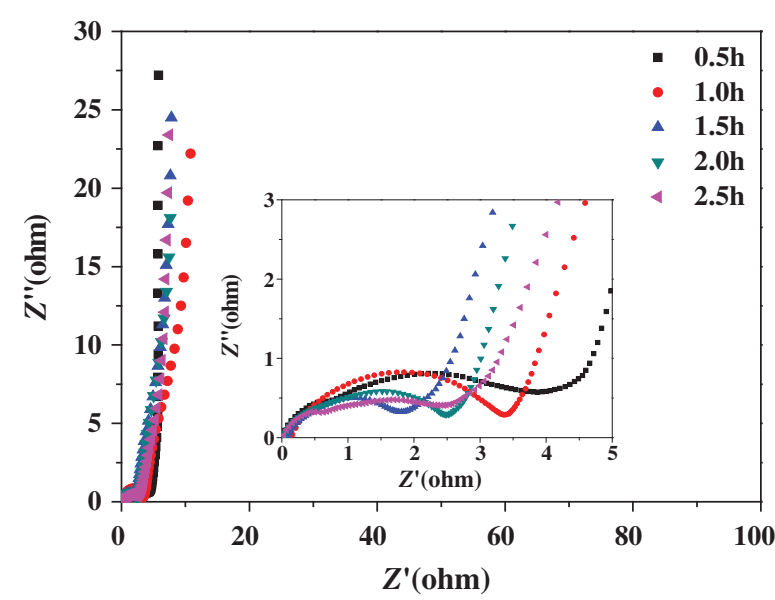

Figure 4. Electrochemical impedance spectra of HACF electrodes with different activation time.

It can be observed from Figure 5(a) that CV curves of HACF self-supported electrode have good symmetry and reproducible capacitance behavior. With the increase of activation time from 0 to $1.5 \mathrm{~h}$, the specific surface area of $\mathrm{HACF}$ increases and a larger $\mathrm{CV}$ area is obtained, which indicates higher capacitance storage. However, with further increase of activation time after $1.5 \mathrm{~h}$, the $\mathrm{CV}$ area decreases because the low specific surface area results in low capacitance storage. As illustrated in Figure 5(b), the $\mathrm{CV}$ curve of HACF activated for $1.5 \mathrm{~h}$ presents obvious

(a)

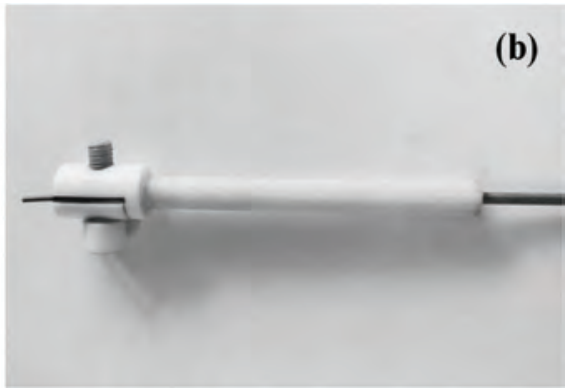

(b)

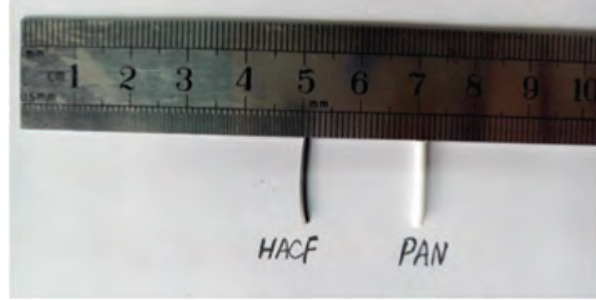

Figure 3. Figures of working electrode (a) HACF electrode and PAN fiber; (b) HACF electrode clipped by fixture. 

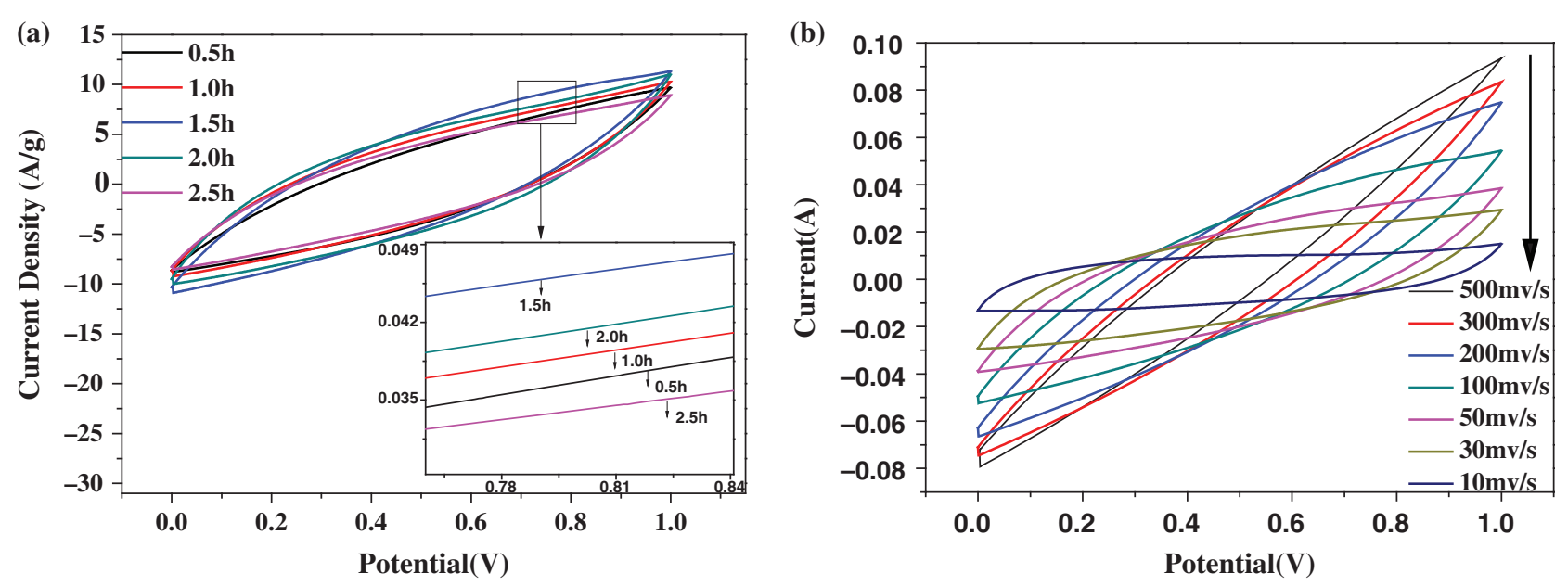

Figure 5. Cyclic voltammograms of HACF electrodes, (a) CV curves of the HACF prepared with different activation time at a scan rate of $100 \mathrm{mV} / \mathrm{s}$; (b) CV curves of the HACF activated for $1.5 \mathrm{~h}$ measured at scan rates of $10 \sim 500 \mathrm{mV} / \mathrm{s}$.

rectangular shape at the scan rate of $10 \mathrm{mV} \mathrm{s}^{-1}$. However, the loop is distorted into an oblique angle when scan rate increases, suggesting internal contact resistance existence in HACF electrode. This is caused by higher scan rate results in faster charge and discharge.

The charge/discharge performance of HACF electrodes with different activation time at $1 \mathrm{~A} \mathrm{~g}^{-1}$ current density is illustrated in Figure 6. Specific capacitances of HACF electrodes are calculated by Eq. (1). Specific capacitances of HACF electrodes activated for $0.5 \mathrm{~h}, 1 \mathrm{~h}, 1.5 \mathrm{~h}, 2.0 \mathrm{~h}$, $2.5 \mathrm{~h}$ are $125 \mathrm{~F} \mathrm{~g}^{-1}, 173 \mathrm{~F} \mathrm{~g}^{-1}, 216 \mathrm{~F} \mathrm{~g}^{-1}, 192 \mathrm{~F} \mathrm{~g}^{-1}$, $150 \mathrm{~F} \mathrm{~g}^{-1}$, respectively. The highest specific capacitance of $\mathrm{HACF}$ electrodes is obtained after $1.5 \mathrm{~h}$ activation, which is coincided with the cyclic voltammogram results. The specific capacitance of HACF is not proportional to the specific surface area. For example, HACF electrode for $2.5 \mathrm{~h}$ activation with the lowest specific surface area possesses a higher specific capacitance than that of HACF electrode for $0.5 \mathrm{~h}$ activation, proving that specific surface area is not the only factor to affect electrochemical performance of HACF.

Galvanostatic charge/discharge curves of the HACF electrodes at various current densities are presented in

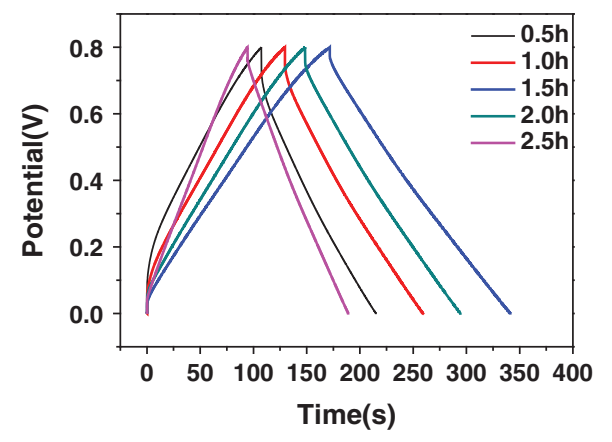

Figure 6. The charge/discharge performance of HACF electrodes with different activation time at $1 \mathrm{~A} \mathrm{~g}^{-1}$.
Figure 7. The results show that the smaller the current density, the higher the specific capacitance HACF electrodes have. Small current density indicates that charge and discharge rate are slow, electrolyte ions have enough time to move into the micropores of HACF electrodes and form an electrochemical double layer structure. Since the HACF electrodes possess large amount of micropores, these pores can be utilized to store charges at low current density. As shown in Figure 7(b), the specific capacitance of HACF electrode activated for $1.5 \mathrm{~h}$ reaches $216 \mathrm{~F} \mathrm{~g}^{-1}, 269 \mathrm{~F} \mathrm{~g}^{-1}, 297 \mathrm{~F} \mathrm{~g}^{-1}, 301 \mathrm{~F} \mathrm{~g}^{-1}, 319 \mathrm{~F} \mathrm{~g}^{-1}$, $323 \mathrm{~F} \mathrm{~g}^{-1}$ at $1 \mathrm{~A} \mathrm{~g}^{-1}, 0.5 \mathrm{~A} \mathrm{~g}^{-1}, 0.3 \mathrm{~A} \mathrm{~g}^{-1}, 0.2 \mathrm{~A} \mathrm{~g}^{-1}$, $0.1 \mathrm{~A} \mathrm{~g} \mathrm{~g}^{-1}, 0.05 \mathrm{~A} \mathrm{~g}^{-1}$, respectively, which is higher than shown for active carbon fiber in other studies, presented in Table II.

The cycle life of the self-supported electrode HACF was investigated. As illustrated in Figure 8, HACF electrode was working under $1 \mathrm{~A} / \mathrm{g}$ with potential window of $0 \sim 0.8 \mathrm{~V}$. The mass specific capacitance of HACF was reduced from $216 \mathrm{~F} / \mathrm{g}$ to $200 \mathrm{~F} / \mathrm{g}$ after 2000 cycles. The results confirmed that $\mathrm{HACF}$ electrode possesses good cycle repeatability.

As illustrated in Figure 9, the results can be illustrated by the scheme diagram of HACF and ACF. HACF electrode has two surfaces from whom pores exposed on the surface directly in Figure 9(a). When bias voltage is applied on the HACF electrodes, both the exposed pore on two surfaces and the finger-like porous can attract the negative ions in electrolyte and store charges. In contrast, ACF working electrodes produced by mixing $\mathrm{HACF}$, acetylene black and PTFE, then kneading and rolling to nickel grid are investigated in many studies. When ACFs electrodes are applied bias voltage, electrolyte ions need more time to reach the pores of ACFs electrodes due to a longer transfer path than that of HACF electrodes (Fig. 9(b)). Even more, electrolyte needs additional time to impregnate the pore of ACFs electrode compared with HACF. In conclusion, 

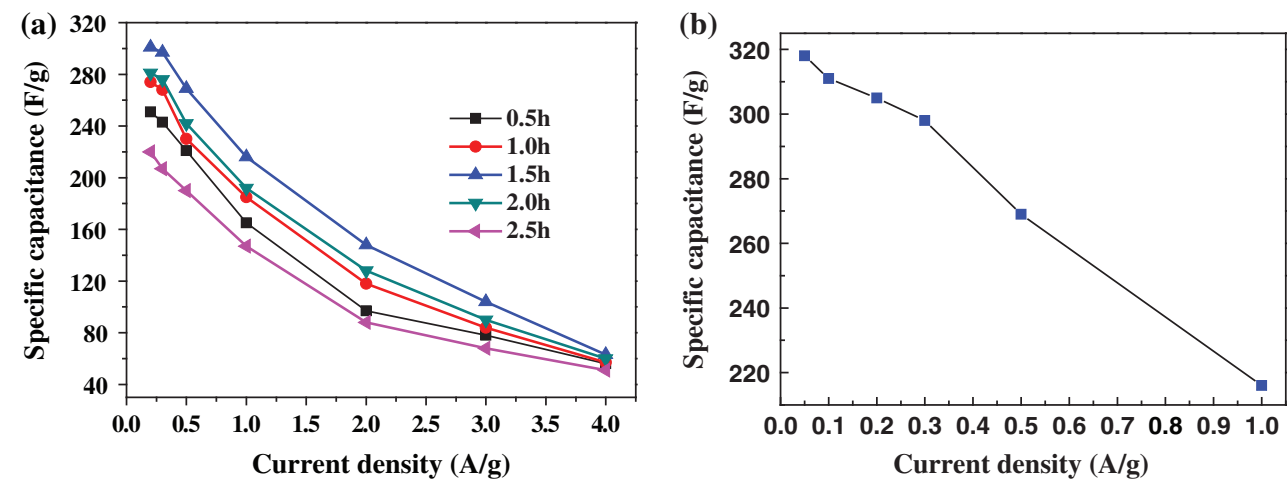

Figure 7. (a) The specific capacitance of HACF electrodes at different current density $\left(0.2 \mathrm{~A} \mathrm{~g}^{-1}, 0.3 \mathrm{~A} \mathrm{~g}^{-1}, 0.5 \mathrm{~A} \mathrm{~g}^{-1}, 1 \mathrm{~A} \mathrm{~g}^{-1}, 2 \mathrm{~A} \mathrm{~g}^{-1}, 3 \mathrm{~A} \mathrm{~g}\right.$, $\left.4 \mathrm{~A} \mathrm{~g}^{-1}\right)$; (b) the specific capacitance of HACF activated by $1.5 \mathrm{~h}$ at different current density $\left(1 \mathrm{~A} \mathrm{~g}^{-1}, 0.5 \mathrm{~A} \mathrm{~g}^{-1}, 0.3 \mathrm{~A} \mathrm{~g}^{-1}, 0.2 \mathrm{Ag}^{-1}, 0.1 \mathrm{~A} \mathrm{~g}^{-1}\right.$, $0.05 \mathrm{~A} \mathrm{~g}^{-1}$ ).

the specific surface area and self-supported structure of HACF electrode are the factors that affect the electrochemical performance and is a promising production methodology.

Table II. Comparison of the specific surface area and specific capacitance of active carbon fiber in different studies.

\begin{tabular}{lcccc}
\hline Samples & $\begin{array}{c}\text { Specific } \\
\text { surface } \\
\text { area }\left(\mathrm{m}^{2} \mathrm{~g}^{-1}\right)\end{array}$ & $\begin{array}{c}\text { Specific } \\
\text { capacitance } \\
\left(\mathrm{F} \mathrm{g}^{-1}\right)\end{array}$ & $\begin{array}{c}\text { Current } \\
\text { density } \\
\left(\mathrm{A} \mathrm{g}^{-1}\right)\end{array}$ & Reference \\
\hline ACF & 597 & 256 & 0.2 & {$[24]$} \\
ACF & 2066 & 194 & 0.05 & {$[38]$} \\
ACF & 804 & 215 & 0.2 & {$[39]$} \\
ACF & 764 & 158 & 1 & {$[40]$} \\
ACF & 3291 & 196 & 0.5 & {$[21]$} \\
ACF & 447 & 222 & 0.1 & {$[41]$} \\
ACF & 2294 & 225 & 0.5 & {$[42]$} \\
ACF & 2100 & 175 & 1 & {$[43]$} \\
ACF & 843 & 208 & 1 & {$[44]$} \\
HACF & 2087 & 287 & 0.05 & {$[28]$} \\
HACF & 1873 & 216 & 1 & In this study \\
& & 269 & 0.5 & \\
& & 301 & 0.2 & \\
& & 319 & 0.1 & \\
\hline
\end{tabular}

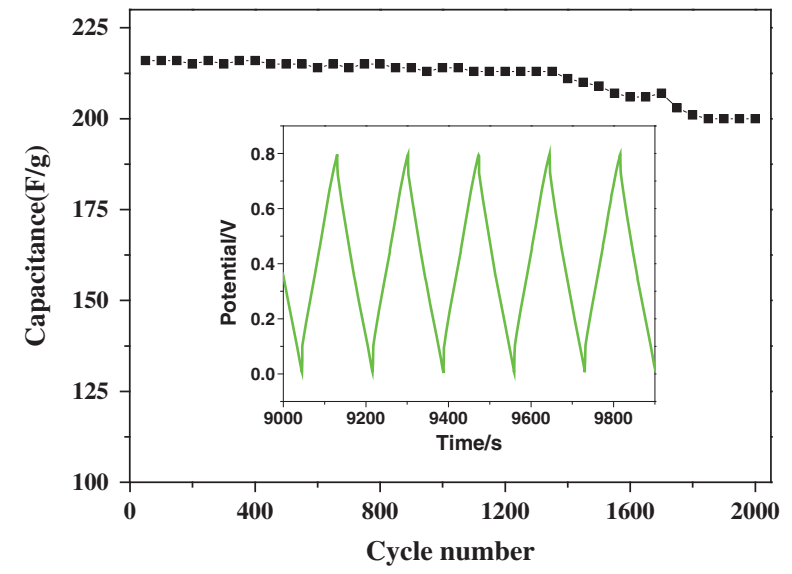

Figure 8. Cycle life of HACF electrode under $1 \mathrm{~A} / \mathrm{g}$. (a)

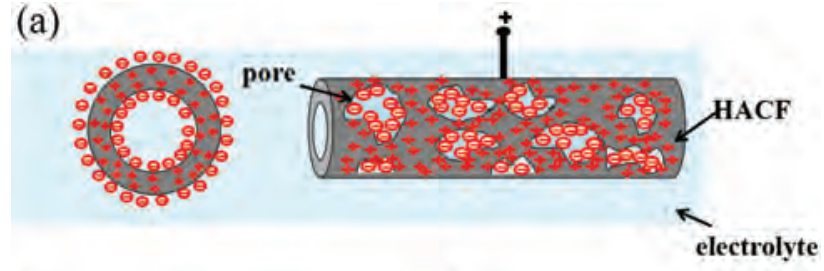

(b)

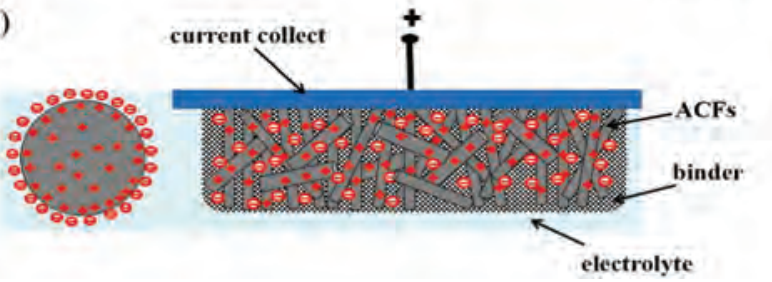

Figure 9. Scheme diagram of HACF electrode and ACFs electrode; (a) HACF; (b) ACFs.

\section{CONCLUSION}

HACF firstly used as self-supported electrode of supercapacitors possessed excellent electrochemical performance. HACF electrode prepared in this paper possess large amount of micropores and large specific surface area of $1873 \mathrm{~m}^{2} / \mathrm{g}$. A maximum specific capacitance of $323 \mathrm{~F} \mathrm{~g}^{-1}$ at $0.05 \mathrm{~A} \mathrm{~g}^{-1}$ and $216 \mathrm{~F} \mathrm{~g}^{-1}$ at $1 \mathrm{~A} \mathrm{~g}^{-1}$ were observed. This was attributed to (i) their special hollow structure as a storage of electrolyte, (ii) its inner and outer surface provide double layer effect, and (iii) micropores or mesopores exposed on the surface to reduce the length of the movement of ions. HACF electrode avoided the negative effect brought by the addition of binder, conductive agent and current collector. Therefore, this study offers new opportunities to prepare HACF self-supported electrode which can be a promising application in supercapacitors.

Acknowledgments: This work was supported by the Key Basic Research Project of Shanghai (13JC1405300, 16JC1403300), the Natural Science Foundation of Shanghai (16ZR1446200) and we also appreciate funding from 
the China Scholarship Council (grant 201806260112) for the joint-Ph.D. study at Ghent university.

\section{References and Notes}

1. Frackowiak, E. and Béguin, F., 2001. Carbon materials for electrochemical storage of energy in capacitors. Carbon, 39, pp.937-950.

2. Simon, P. and Gogotsi, Y., 2008. Materials for electrochemical capacitors. Nature Materials, 7, pp.845-854.

3. Wang, G.P., Zhang, L. and Zhang, J.J., 2012. A review of electrode materials for electrochemical supercapacitors. Chemical Society Reviews, 41, pp.797-828.

4. Wang, X.Z., Zeng, X.F. and Cao, D.P., 2018. Biomass-derived nitrogen-doped porous carbons (NPC) and NPC/polyaniline composites as high performance supercapacitor materials. Engineering Sciences, 1, pp.55-63.

5. Li, X.M., Zhao, W., Yin, R., Huang, X.S. and Qian, L., 2018 A highly porous polyaniline-graphene composite used for electrochemical supercapacitors. Engineering Sciences, 3, pp.89-95.

6. Ran, F.T., Yang, X.B. and Shao, L., 2018. Recent progress in carbonbased nanoarchitectures for advanced supercapacitors. Advanced Composites and Hybrid Materials, 1, pp.32-55.

7. Du, H.Y., Zhao, X.X., Lin, J., Guo, J., Wang, B., Hu, Z., Shao, Q., Pan, D., Wujcik, E.K. and Guo, Z.H., 2018. Carbon nanomaterials in direct liquid fuel cells. Chemical Record, 18, pp.1365-1372.

8. Lin, C.F., Hu, L., Cheng, C.B., Sun, K., Guo, X.K., Shao, Q., Li, J.B., Wang, N. and Guo, Z.H., 2018. Nano- $\mathrm{TiNb}_{2} \mathrm{O}_{7} /$ carbon nanotubes composite anode for enhanced lithium-ion storage. Electrochimica Acta, 260, pp.65-72.

9. Hou, Q.Z., Ren, J., Chen, H.J., Yang, P., Shao, Q., Zhao, M., Zhao, X.C., He, H.C, Wang, N., Luo, Q. and Guo, Z.H., 2018. Synergistic hematite-fullerene electron-extracting layers for improved efficiency and stability in perovskite solar cells. ChemElectroChem, 5, pp.726-731.

10. Koo, Y., Shanov, V.N., Yarmolenko, S., Schulz, M., Sankar, J. and Yun, Y., 2015. Inverse-ordered fabrication of free-standing CNT sheets for supercapacitor. Langmuir, 31, pp.7616-7622.

11. $\mathrm{Hu}, \mathrm{S}$., Rajamani, R. and $\mathrm{Yu}, \mathrm{X}$., 2012. Flexible solid-state paper carbon nanotube supercapacitor. Applied Physics Letters, 100, pp.104103-104106.

12. $\mathrm{Su}, \mathrm{F}$. and Miao, M., 2014. Asymmetric carbon nanotube- $\mathrm{MnO}_{2}$ twoply yarn supercapacitors for wearable electronics. Nanotechnology, 25, pp.135401-135408.

13. Kim, K.M., Lee, Y.G., Shin, D.O. and Ko, J.M., 2016. Supercapacitive properties of activated carbon electrode in potassiumpolyacrylate hydrogel electrolytes. Journal of Applied Electrochemistry, 46, pp.567-573.

14. Teng, Y., Liu, E.H. and Ding, R., 2016. Bean dregs-based activated carbon/copper ion supercapacitors. Electrochimica Acta, 194, pp.394-404.

15. Xie, Q.X., Zheng, A., Zhai, S.B., Wu, S.H., Xie, C., Zhang, Y.F. and Guan, Y.F., 2015. Reed straw derived active carbon/graphene hybrids as sustainable high-performance electrodes for advanced supercapacitors. Journal of Solid State Electrochemistry, 20, pp.449-457.

16. Zhu, Y.W., Murali, S., Stoller, M.D., Ganesh, K.J., Cai, W.W., Ferreira, P.J., Pirkle, A., Wallace, R.M., Cychosz, K.A., Thommes, M., Dong, S., Stach, E.A. and Ruoff, R.S., 2011. Carbonbased supercapacitors produced by activation of graphene. Science, 332, pp.1537-1541.

17. Maher, F., Kady, E., Veronica, S., Sergey, D.B. and Kaner, B.R., 2012. Laser scribing of high-performance and flexible graphenebased electrochemical capacitors. Science, 335, pp.1326-1330.

18. Aphale, A., Maisuria, K., Mahapatra, M.K., Santiago, A., Singh, P. and Patra, P., 2015. Hybrid electrodes by in-situ integration of graphene and carbon-nanotubes in polypyrrole for supercapacitors. Scientific Reports, 5, pp.14445-14452.
19. Su, C.I., Wang, C.M., Lu, K.W. and Shi, W.C., 2014. Evaluation of activated carbon fiber applied in supercapacitor electrodes. Fibers and Polymers, 15, pp.1708-1714.

20. Hu, S.X., Zhang, S.L., Pan, N. and Hsieha, Y.L., 2014. High energy density supercapacitors from lignin derived submicron activated carbon fiber in aqueous electrolytes. Journal of Power Sources, 270, pp.106-112.

21. $\mathrm{Xu}, \mathrm{B} ., \mathrm{Wu}, \mathrm{F}$. , Chen, R.J., Cao, G.P., Chen, S. and Yang, Y.S., 2010. Mesoporous activated carbon fiber as electrode material for high-performance electrochemical double layer capacitors with ionic liquid electrolyte. Journal of Power Sources, 195, pp.2118-2124.

22. Inagaki, M., 2010. Pores in carbon materials-Importance of their control. New Carbon Materials, 24(3), pp.193-232.

23. Frackowiak, E., 2007. Carbon materials for supercapacitor application. Physical Chemistry Chemical Physics, 9, pp.1774-1785.

24. Ma, C., Song, Y., Shi, J.L., Zhang, D.Q., Zhai, X.L., Zhong, M., Guo, Q.G. and Liu, L., 2013. Preparation and one-step activation of microporous carbon nanofiber for use as supercapacitor electrodes. Carbon, 51, pp.290-300.

25. Inagaki, M., Konno, H. and Tanaike, O., 2010. Carbon materials for electrochemical capacitors. Journal of Power Sources, 195, pp.7880-7903.

26. Kötz, R. and Carlen, M., 2000. Principles and applications of electrochemical capacitors. Electrochimica Acta, 45, pp.2483-2498.

27. Zhang, W., Yan, X.Y. and Tong, X.L., 2015. Self-supported hierarchical hollow-branch cobalt oxide nanorod arrays as binder-free electrodes for high-performance lithium ion batters. Materials Letters, 162, pp.101-104.

28. Du, X., Zhao, W. and Wang, Y., 2013. Preparation of activated carbon hollow fibers from ramie at low temperature for electric double-layer capacitor applications. Bioresource Technology, 149, pp.31-37.

29. Chen, Z.H., Christensen, L. and Dahn, J.R., 2003. Comparison of PVDF and PVDF-TFE-P as binders for electrode materials showing large volume changes in lithium-ion batters. Molecular Cancer Therapeutics, 150, pp.1952-1961.

30. Yan, F., Zhu, C.L., Wang, S., Zhao, Y., Zhang, X.T., Li, C.Y. and Chen, Y.J., 2016. Electrochemically activated-iron oxide nanosheet arrays on carbon fiber cloth as a three-dimensional self-supported electrode for efficient water oxidation. Journal of Materials Chemistry A, 4, pp.6048-6055.

31. Hao, L., Shen, L.F., Wang, J., Xu, Y.L. and Zhang, X.G., 2016. Hollow $\mathrm{NiCo}_{2} \mathrm{~S}_{4}$ nanotube arrays grown on carbon textile as a selfsupported electrode for asymmetric supercapacitors. RSC Advances, 2, pp.9950-9957.

32. Xin, G.X., Wang, Y.H., Liu, X.X., Zhang, J.H., Wang, Y.F., Huang, J.J. and Zang, J.B., 2015. Preparation of self-supporting graphene on flexible graphite sheet and electrodeposition of polyaniline for supercapacitor. Electrochimica Acta, 167, pp.254-261.

33. Li, W.W., Gan, L., Guo, K., Ke, L.B., Wei, Y.Q., Li, H.Q., Shen, G.Z. and Zhai, T.Y., 2016. Self-supported $\mathrm{Zn}_{3} \mathrm{P}_{2}$ nanowire arrays grafted on carbon fabrics as an advanced integrated anode for flexible lithium ion batters. Nanoscale, 8, pp.8666-8672.

34. Zhang, L.J., Jiang, Y.Z., Wang, L.W., Zhang, C. and Liu, S.X., 2016. Hierarchical porous carbon nanofiber as binder-free electrode for high-performance supercapacitor. Electrochimica Acta, 196, pp.189-196.

35. Zhang, L.J., Hui, K.N., Hui, K.S., Chen, X., Chen, R. and Lee, H., 2016. Role of graphene on hierarchical flower-like NiAl layered double hydroxide-nickel foam-graphene as binder-free electrode for high-rate hybrid supercapacitor. International Journal of Hydrogen Energy, 41, pp.9443-9453.

36. Huang, H.B., Huang, H., Yao, J., Li, L., Zhu, F. and Liu, Z., 2016. Reinforced polyaniline/polyvinyl alcohol conducting hydrogel from a freezing-thawing method as self-supported 
electrode for supercapacitors. Journal of Materials Science, 51, pp.8728-8736.

37. Zhao, H.Y., Wang, L.X., Jia, D.Z., Xia, W., Li, J. and Guo, Z.P., 2014. Coal based actived carbon fiber prepared by electrospinning. Journal of Materials Chemistry A, 2, pp.9338-9344.

38. Yue, S.F., Ma, L., Bin, X.U. and Mo, C., 2011. Activated carbon fiber felt used directly as electrode for supercapacitor. Battery Bimonthly, 41, pp.62-65.

39. Lea, T.H., Yang, Y., Huang, Z.H. and Kang, F.Y., 2015. Preparation of microporous carbon nanofiber from polyimide by using polyvinyl pyrrolidone as template and their capacitive performance. Journal of Power Sources, 278, pp.683-692.

40. Lin, J.H., Ko, T.H., Lin, Y.H. and Pan, C.K., 2009. Various treated conditions to prepare porous activated carbon fiber for application in supercapacitor electrodes. Energy Fuels, 23, pp.4668-4677.
41. Ying, L., Chun, Z.S. and Xiang, L.C., 2015. Preparation of nitrogenenriched porous carbon fiber as supercapacitor electrode materials. New Carbon Materials, 30, pp.295-301.

42. Huang, Y.X., Peng, L.L., Liu, Y., Zhao, G.J., Chen, J.Y. and Yu, G.H., 2016. Biobased nano porous active carbon fiber for highperformance supercapacitors. ACS Applied Materials \& Interfaces, 8, pp.15205-15215.

43. Kim, C., Choi, Y.O., Lee, W.J. and Yang, K.S., 2004. Supercapacitor performances of activated carbon fiber webs prepared by electrospinning of PMDA-ODA poly(amic acid) solutions. Electrochimica Acta, 50, pp.883-887.

44. Xu, B., Wu, F., Chen, S., Zhang, C.Z., Cao, G.P. and Yang, Y.S., 2007. Activated carbon fiber cloths as electrodes for high performance electric double layer capacitors. Electrochimica Acta, 52, pp.4595-4598.

Received: 24 October 2018. Accepted: 23 May 2019. 